\title{
Supply Chain Logistics Business Process Reengineering of Automobile Spare Parts Based on SCOR
}

\author{
Ming Li \\ School of Management, Guangxi University of Science and \\ Technology, LiuZhou, GuangXi P.R. China \\ wuqingmingjian@qq.com
}

\author{
Xiang Zhai \\ IS\&S Dept, SAIC-GM-Wuling Automobile Co., Ltd, \\ LiuZhou, GuangXi, P.R. China \\ xiang.zhai@sgmw.com.cn
}

\author{
Fangli Qin \\ 2011 levels of information management and information system, School of Management, Guangxi University of Science and \\ Technology, LiuZhou, GuangXi, P.R. China \\ fangliqin@qq.com
}

\section{AN AUTO PARTS SUPPLY CHAIN LOGISTICS BUSINESS OVERVIEW}

Typical automotive parts logistics business as automobile logistics service providers, OEMs machine undertake domestic and international logistics business, but also to carry out the engine, transmission and other parts procurement and production and distribution business. The traditional auto parts logistics enterprises are generally predecessor as OEMs logistics department, along with restructuring stripped out. Therefore, its organizational structure and business processes are different businesses around the OEMs were established in recent years with the expansion of automotive spare parts logistics enterprise business, expanding logistics resources and low resource utilization increasingly stark a contradiction. Urgently needed to build the company's business operations such as, process reengineering and logistics information platform.

\section{A. Automobile spare parts logistics enterprise information} needs

Most auto parts logistics enterprises have not yet been fully established full network management network visualization and intelligent, but some companies have used some of the primary applications. Currently, car spare parts logistics companies hope that through the construction of logistics information integration platform, making the dispatch center, storage platforms, between teams can be based on logistics information sharing and collaborative transportation and distribution synergies. On this basis, the company carried out within the homogeneous or heterogeneous system integration, the formation of integrated logistics platform, logistics information technology to meet the application requirements.

1) Expand the scope of business logistics platform

Currently, the upstream OEMs logistics business in addition to auto parts logistics business, there are some other TPL providers, companies need to constantly improve the logistics integration platform based on the scope of the order, to respond to future purchase more parts, vehicle and spare parts business, and expand their market share. 
2) Improve the logistics system data interface

With the upstream OEM production capacity and strengthen information technology, data exchanges both systems will be very frequent, import and export via telephone, e-mail and spreadsheets methods can not meet the needs of future logistics operations, the development of more types of business systems data interfaces to transmit information is imperative, auto parts logistics companies need to continually improve the data interface with OEM systems, automated order information sources.

3) To achieve the automatic billing logistics business

Because of the many product lines and OEM models, different models, different models, different quantities shipped, different destinations have different billing methods, international business and domestic settlement business is different, the entire settlement process is complicated, large most auto parts logistics enterprises currently settled at the upstream and downstream, are checked by hand, time-consuming and laborious. The latter will achieve downstream automated clearing mode, the system supports the month, week, day settlement, settlement officers to reduce the workload and improve the speed and accuracy of the settlement.

\section{4) To build an open platform for integrated logistics}

With the development of automobile spare parts logistics enterprises, the need to form the basis of an open system platform, form the system architecture can be extended, integration of enterprise resource future platforms. Driven value chain including logistics business participants in all aspects of sub-suppliers and customers, including the standardization of information systems management, so as to enhance the overall level of information in the region in the automotive supply chain logistics industry, promote the development of the automotive supply chain logistics industry and bring relevant social benefits.

\section{B. Situation auto parts logistics business processes}

Typical auto parts logistics business logistics business, for example, mainly involving raw materials and parts procurement, production parts distribution business, vehicle sales service and spare parts business. General logistics enterprises in accordance with the above different logistics business or customer-related departments will set up specialized management, such as the establishment of vehicle business unit is responsible for vehicle related logistics services, the establishment of production and distribution and distribution business unit parts management, the establishment of purchased parts and spare parts business unit to manage the procurement of parts and spare parts, as shown in Figure 1. More diverse range of businesses both receive orders, process orders, the main part of the cargo out of the library, shipping, in-transit tracking, customer receipt and freight settlement value of the value chain. Thus forming a vertically integrated logistics business SCOR model based on different services.

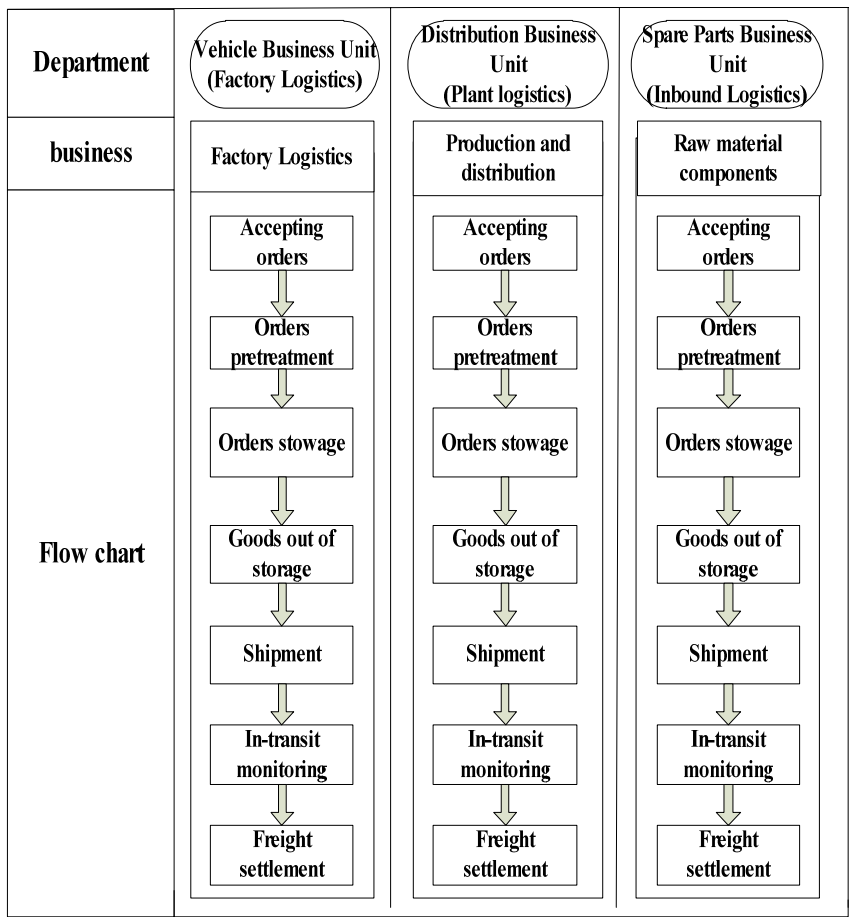

Figure 1. BPR before SCOR departments and processes of vertical integration model

\section{Auto parts logistics enterprise logistics management problems}

In the figure formed departments and processes SCOR model of vertical integration, through the automotive supply chain environment and related business practice in-depth analysis, we found that the current organizational structure of the enterprise and business processes are mainly oriented to different customers , that is, for different customer groups set up special organizations related to logistics, finance, etc., although doing so can improve service levels, and increase customer satisfaction, but there are a lot of disadvantages, such as each customer has a dedicated related services personnel, which resulted in duplicate staffing due to different customer's goods are independent of transport, which resulted in the distribution of the vehicle loading rate is not higher following two major problems.

1) Bloated staff repeat

Between different departments in accordance with the different business or customer set up a similar business model, from receiving orders, handling, loading, a library, tracking, receiving and clearing link is highly accessible work, according to the business sector is even a lot of repetition, this has led to bloated enterprise organizations, institutions duplication between different services; in addition, the same logistics nodes of different services need to be equipped with the appropriate logistics operator, resulting in the logistics business people working the large number of repeat business. 
2) Operate independently, it is difficult optimal

Type of business in all sectors are independent, separate logistics operation, it is difficult to carry out all kinds of different logistics business enterprise-class monitoring, such as the inability to achieve vehicle stowage and spare parts, it is difficult to reduce costs; orders can't achieve the whole process monitoring, only their own array. Such companies can't integrate various logistics resources within the enterprise, it is difficult to achieve efficient allocation of resources in order to achieve global optimization.

\section{SCOR MODEL BASED ON THE VALUE CHAIN AND BPR OVERVIEW}

\section{A. Value Chain Overview}

Harvard Business School professor Michael Porter's "Every business is in the design, production, marketing, sending and supporting its products to various activities carried out during an assembly in 1985. All of these activities can be a value chain show "enterprise value creation is constituted by a series of activities, these activities can be divided into two types of basic activities and support activities, basic activities including internal logistics, production operations, external logistics, marketing and sales, and service; while ancillary activities include procurement, technology development, human resource management and enterprise infrastructure. These differ from each other but interrelated production and business activities, constitute a dynamic process of creating value, that value chain. Value chain in economic activity is everywhere, there is trade between the upstream and downstream value chain associated with the enterprise business, contact the company's internal business units constitute the enterprise value chain, there are also among the business units within the enterprise value chain link.

\section{B. SCOR Model Overview}

The International Supply Chain Council develop the SCOR to support different industrial areas of supply chain operations reference model. Is the first cross-industry supply chain in different standard process reference model, is also a common language and processes diagnostic tool supply chain management. SCOR model consists of four parts: supply chain management processes are generally defined process performance indicators corresponding to the benchmarks, description, and choose the product information supply chain software supply chain "best practices" (best practices) of. SCOR model supply chain is defined as plan (Plan), procurement (Source), production (Make), distribution (Deliver), Return (Return) five processes, and were cut from the supply chain division, configuration and process elements of three levels, describe the various processes of the standard definition, the corresponding performance metrics for each process, providing supply chain "best practices" and human resources programs.

\section{BPR theory Overview}

Logistics enterprises of Automobile spare parts implement BPR, including organizational restructuring, reorganization of core competence, technological reorganization, restructuring and other human resource content. The basic process can be recycled in accordance with the life cycle process approach to the implementation of the whole process reengineering analysis. Specific implementation can be divided into the following four levels: as shown in Figure 2:

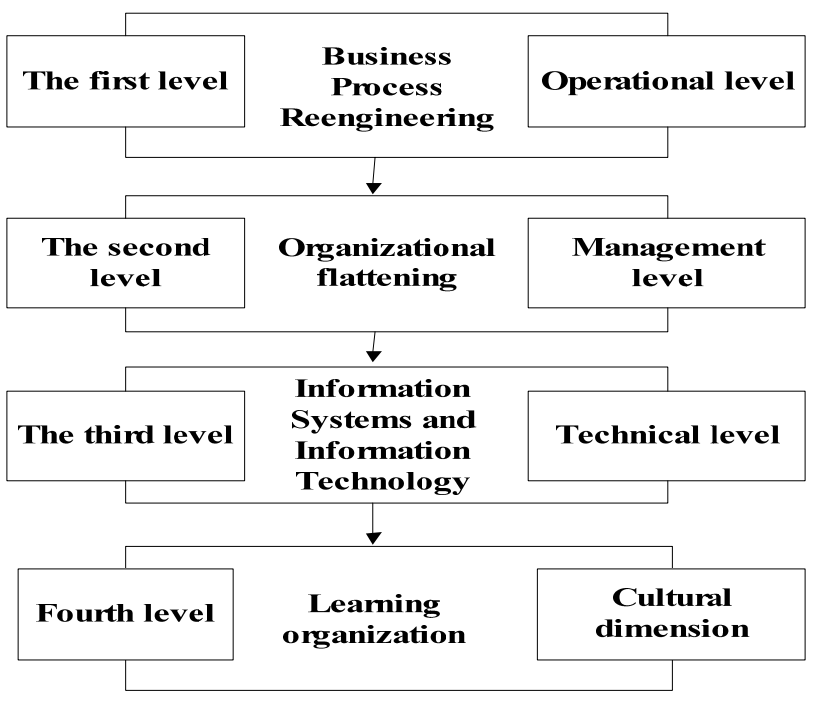

Figure 2. auto parts logistics enterprises BPR guiding ideology

\section{SCOR-BASED AUTO PARTS LOGISTICS ENTERPRISES BPR OVERVIEW}

\section{A. auto parts logistics enterprises BPR features}

Currently, the focus has been China's auto parts logistics business process reengineering from internal management to a multi-function, multi-organizational and process-oriented customers. Compared with the traditional division of labor based on the theory of management thinking, automobile spare parts logistics enterprises BPR has two notable features:

1) For OEMs, emphasizing the needs of OEMs

In the past, OEMs are passive recipients of logistics services, there is little room optional. But with the increasingly fierce competition and the increasing demand for automotive spare parts logistics companies shift from a seller's to a buyer's market, OEM service from passive recipients to active service efficiency drivers. OEMs need to be the most fundamental driving force auto parts logistics enterprises to implement the BPR.

2) For the core business of logistics business processes

In the traditional division of labor principles, organizational structure traditional logistics companies divided by function, it is difficult to guarantee access to the best overall performance. BPR is to completely break the theoretical division of labor theory of constraints, across functions outside the box, to the logistics process as the core enterprise operating mechanism and organizational restructuring consistent with the logistics process, making 
auto parts logistics enterprises can truly provide in accordance with the needs of OEMs professional logistics services.

\section{B. Guiding ideology of automotive spare parts logistics enterprises BPR}

BPR is an important part of China's auto parts logistics business strategy. Typical automotive parts logistics companies need to have organizational structure and business processes in-depth analysis, then, based on the theory of knowledge value chain and SCOR models of organization was restructured and redesigned business processes. Meanwhile, around the development of business process reengineering "order-based logistics supply chain integration platform" to achieve a new business process and information technology implementation in parallel, nurture and develop the core competitiveness of enterprises.

Organization of logistics enterprises are generally divided into two different ways: logistics services around the object of the Value Chain; build around the logistics value chain of the business itself. SCOR's BPR is based from the original focus on customer value chain, value chain logistics operations turned around during this time of logistics services and logistics companies target their business processes conducted in-depth analysis, analysis of the logistics supply chain value distribution improve logistics and resource utilization, speed up the logistics has a high response speed reference.

\section{Based on SCOR auto parts logistics enterprises to implement BPR}

SCOR use of value chain optimization ideas, the different business or a different customer's logistics business in accordance with all aspects of logistics services to restructure itself, breaking the original departmental boundaries. The original vehicle operations, production and distribution operations, procurement same parts and spare parts logistics business process aspects of horizontal integration business unit were the same or similar businesses in different sectors of centralized management, the formation of the organization based on the nature of the process stream. For example, order receiving, processing and tracking of orders based customer service department, job management section of path planning and order stowage of cargo out of storage management, horizontal integration, such as warehousing and distribution department and other departments. As shown in Figure 3:

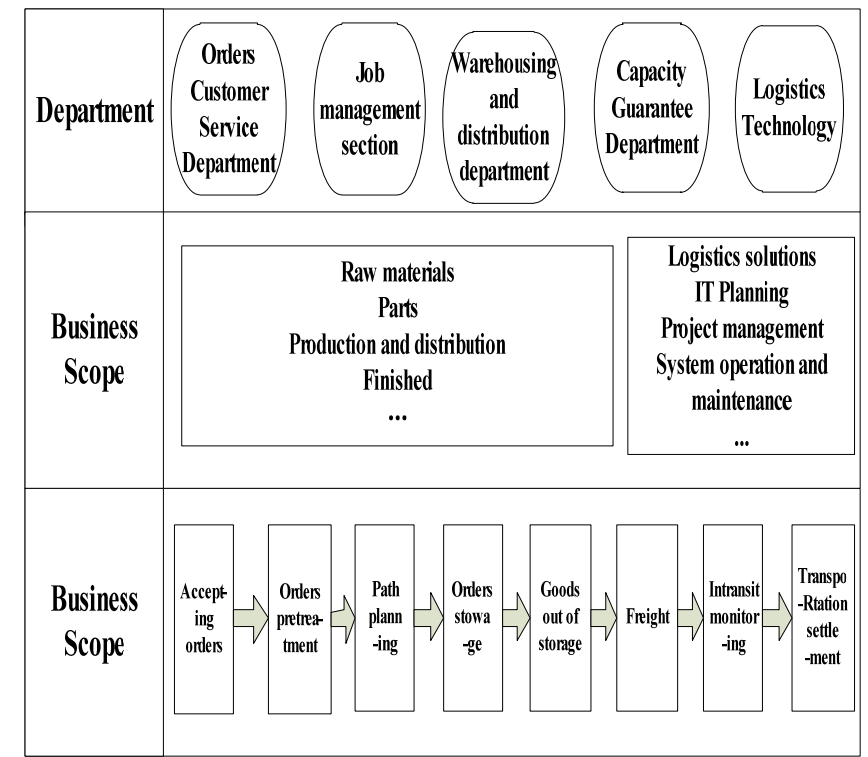

Figure 3. BPR departments and processes after the SCOR model of horizontal integration

Adjusted after the reorganization of the organizational structure and business processes, can enhance the professional standards of the various functional departments, unified management of orders can also generate revenue intensification. By order based on logistics information integration platform, the integration of different resources in the automotive supply chain, enterprise resource utilization in the automotive spare parts logistics industry, while the aid enterprise logistics operations segment platform will make logistics operations each ring is tight interlocking. Major advance the following two aspects:

1) A flat organization, streamlining staff

After the reorganization of the organizational structure tends to flatten and streamline staff, similar logistics nodes of different services significantly reduced the number of personnel required for the operation, after the reorganization process in accordance with the logistics division of the department in which the logistics nodes, process more clear and reasonable. Through the implementation of the order based on logistics information integration platform, automotive spare parts logistics industry has changed some extensive management consistent image for OEMs to provide a fine stream of dynamic information. Help to improve the corporate image and create a good corporate culture.

2) Coordinated operation, the global optimum

After the reorganization, corporate executives can make orders for all types of business globally control the whole process, comprehensive and reasonable path planning. Enhance the operational efficiency of the logistics company, which can be mixed with a carrier, and reduce costs. Relying on the automotive supply chain, companies get a steady stream of business, although the business is stable, but it also brings the core competitiveness is not outstanding 
issues, and this along with the implementation of logistics information integration platform for companies to build their own core competitiveness solid step, coming around the logistics information integration platform based on the order, will implement the operational level, the various decision-making system, eventually playing on information technology, automotive spare parts logistics industry leading core competence based.

\section{CONCLUSION}

This paper studies the automobile value chain logistics distribution of spare parts supply chain, to explore the relationship between the SCOR model of logistics resource allocation and organization structure, based on business process, and based on the premise of maximum efficiency in the use of logistics resources, based on the premise of maximum efficiency in the use of logistics resources, According to the change of the traditional business mode of operation of the logistics division of vertical integration become according to operation mode of horizontal integration logistics order management, enhance the professional level of the various functional departments, unified management of orders can also produce intensive income, To provide reference for the related logistics enterprises.

\section{ACKNOWLEDGMENT}

This research was financially supported by Guangxi autonomous region level and the National college students' innovation and entrepreneurship training plan project :"Research on supply chain logistics information integration and innovation of intelligent multi-agent system based on auto parts enterprises" (Guangxi autonomous region level project number: 201410594088)/( National project number: 201410594036)

\section{REFERENCES}

[1] Yuan Yan, Data supply chain management systems and logistics technology in the field of integration of research [J]. Logistics Technology. 2013 (13):12-15

[2] Yan ZhanBei. Upgrade dilemma facing our industry chain cluster and its strategy crack [J]. Science and Technology Progress and Policy .2011 (12):20-24

[3] Xu XuanGuo, Liu Fei, Wang YunFei. Based on SCOR for manufacturing enterprise production logistics model and its application [J]. science and technology management research. 2013 (13):13-24

[4] Xie Lei, Empirical Study of the mechanism of processing and assembly collaboration influence supply logistics and chain[D]. Huazhong University of Science and Technology, Management Science and Engineering .2013 (21-34)

[5] Gao Xue Yong, Fusion based logistics chain and manufacturing supply chain integration field theory[D]. Chang'an University, Logistics Engineering and Management, 2014(25-33 